\title{
IMPACT ABRASION OF HYDRAULIC STRUCTURES CONCRETE
}

\author{
Yu-Wen Liu \\ Department of Civil and Water Resource Engineering, National Chiayi University, Chiayi, Taiwan, R.O.C., \\ yuwen@mail.ncyu.edu.tw \\ Shi-Wei Cho \\ Department of Architecture, China University of Science and Technology, Taipei, Taiwan, R.O.C. \\ Tsao-Hua Hsu \\ Department of Construction, Taipower Company, Taipei, Taiwan, R.O.C.
}

Follow this and additional works at: https://jmstt.ntou.edu.tw/journal

Part of the Civil and Environmental Engineering Commons

\section{Recommended Citation}

Liu, Yu-Wen; Cho, Shi-Wei; and Hsu, Tsao-Hua (2012) "IMPACT ABRASION OF HYDRAULIC STRUCTURES CONCRETE," Journal of Marine Science and Technology: Vol. 20: Iss. 3, Article 2.

DOI: $10.51400 / 2709-6998.1801$

Available at: https://jmstt.ntou.edu.tw/journal/vol20/iss3/2

This Research Article is brought to you for free and open access by Journal of Marine Science and Technology. It has been accepted for inclusion in Journal of Marine Science and Technology by an authorized editor of Journal of Marine Science and Technology. 


\section{IMPACT ABRASION OF HYDRAULIC STRUCTURES CONCRETE}

Acknowledgements

This paper was supported by the Taiwan National Science Council under NSC 94-2211-E-415-003.

This research article is available in Journal of Marine Science and Technology: https://jmstt.ntou.edu.tw/journal/ 


\title{
IMPACT ABRASION OF HYDRAULIC STRUCTURES CONCRETE
}

\author{
Yu-Wen Liu ${ }^{1}$, Shi-Wei $\mathrm{Cho}^{2}$, and Tsao-Hua $\mathrm{Hsu}^{3}$
}

Key words: abrasion, hydraulic structure, impact.

\begin{abstract}
Most of the abrasion damage is caused by the action of water-borne particles (silt, sand, gravel, and other solid) impacting and rolling against the concrete surface during hydraulic structure operation. In this paper solid-particle abrasion of concrete containing slag was studied. Experiments included use of river sand abrade of mean diameter $\sim 0.6,1.2$, 2.5 and $5 \mathrm{~mm}$, and sand content was 110,230 and $340 \mathrm{~kg}$ per $1 \mathrm{~m}^{3}$ of water, impacting at $30^{\circ}, 45^{\circ}$ and $90^{\circ}$ to the concrete surface. And the waterborne sand flow impact test method was used. Test results show that the abrasion rate to be a strong function of erodent size and waterborne sand content. As the erodent size increased from $0.6 \mathrm{~mm}$ to $1.2 \mathrm{~mm}, 2.5 \mathrm{~mm}$, then to $5 \mathrm{~mm}$, the abrasion rate of concrete increased from $100 \%$ to $217 \%$ and $367 \%$. The waterborne sand content was 110,230 and $340 \mathrm{~kg} / \mathrm{m}^{3}$ and the abrasion rate of concrete is 22-56 times of none sand water. Moreover, the abrasion rate of concrete impacted at $90^{\circ}$ was higher than of that of $30^{\circ}, 45^{\circ}$ and $60^{\circ}$.
\end{abstract}

\section{INTRODUCTION}

In Taiwan, all rivers originate from the peak of each ridge, snaking through valleys and running across sporadic plains to reach the ocean. Because of high ridge peaks and steep valley basins, all rivers are short and steep causing rapid flow during storms, particularly during the typhoon season. There is a high average annual rainfall of $2530 \mathrm{~mm}$ in Taiwan, approximate 2.6 times of world average rainfall. In addition, the type and space distribute of rainfall do not exceed each other much. The rainfall is concentrated in the month of May to October, where approximately $78 \%$ of the average annual rainfall occurs [4]. Furthermore, because of the country's frequent earth-

Paper submitted 03/25/11; revised 06/26/11; accepted 09/01/11. Author for correspondence: Yu-Wen Liu (e-mail: yuwen@mail.ncyu.edu.tw).

${ }^{I}$ Department of Civil and Water Resource Engineering, National Chiayi University, Chiayi, Taiwan, R.O.C.

${ }^{2}$ Department of Architecture, China University of Science and Technology, Taipei, Taiwan, R.O.C.

${ }^{3}$ Department of Construction, Taipower Company, Taipei, Taiwan, R.O.C. quakes and fragile geology, the rapid flow of rivers carries heavy sand and gravel, making the sediment yield per area and sand contents of river more than ten times that of the world average. As a result, the most significant abrasion problems happen due to the abrasion effect of the friction and impact of waterborne sand on the hydraulic structures concrete surface.

When concrete surface subjected to a hydraulic impingement of waterborne sand, in the beginning, the surface layer of mortar gradually wears out and the coarse aggregate becomes subsequently exposed. Next, the coarse aggregates are fractured or plucked away, and this is attributed to the waterborne particle impacts and results in the formation of tiny voids in mortar along aggregate surfaces. The formation of voids is profoundly influenced by the coarse aggregate size, the kind of sand used, and the momentum of the rotating water-jet that the formation of voids to penetrate further into the interior region of concrete. When a brittle material is impacted by a hard sharp particle, the contact area is plastically deformed due to the high compressive and shear stresses and a radial crack is formed. After the impact, the plastic deformation leads to large tensile stresses that resulted in lateral cracks causing the material removal $[7,8]$. Abrasion condition and abrade characteristics also play key roles in determining abrasion rate. Large, hard particles are expected to import maximum abrasion rate. Large abrade particles flow much better than small one, and the debris that forms with import by larger abrades is larger [6].

There are many types of abrasion test methods because there are many types of abrasions, and because there are a lot of different situations in which abrasion can become a problem. The existing test methods and experiments $[2,3,10]$ carried out by researchers in each specific scenario reflect that the experiments were carried out to determine frictional attrition involving the impingement of water flow containing a limited amount of tiny grains on a rather small concrete surface area. Generally, abrasion resistance depends on the microstructure of the paste, with the interface between mortar and coarse aggregate species being of primary importance. It seems that the existing abrasion methods can be improved by applying of a water jet containing a proper amount of sand to simulate the abrasion erosion of concrete that actually takes place in the field.

In this paper the waterborne sand flow test which combining the water-jet impact load and sand particle shear/friction 
Table 1. Concrete mix proportions, $\left(\mathrm{kg} / \mathrm{m}^{3}\right)$.

\begin{tabular}{|c|c|c|c|c|c|c|c|}
\hline Batch & $w / c m$ & Water & Cement & Slag & Sand & Gravel & SP \\
\hline C28 & 0.28 & 160 & 457 & 114 & 730 & 925 & 12.5 \\
\hline C36 & 0.36 & 160 & 356 & 89 & 780 & 985 & 10.9 \\
\hline C50 & 0.50 & 160 & 256 & 64 & 820 & 1070 & 0.5 \\
\hline
\end{tabular}

Table 2. Compressive strength and slump of concrete.

\begin{tabular}{|c|c|c|}
\hline Batch & Slump $(\mathrm{cm})$ & Compressive strength (MPa) \\
\hline C28 & 24 & 90.8 \\
\hline C36 & 22 & 50.3 \\
\hline C50 & 21 & 30.4 \\
\hline
\end{tabular}

forces produced by a hydro-particle flow, was used to investigated the effect of impact angle, abrade particles size on abrasion resistance of hydraulic concrete.

\section{EXPERIMENTAL PROGRAM}

\section{Materials}

Materials used in manufacturing test slabs include: (1) Type I Portland cement (ASTM C150); (2) river sand having a fineness of 2.95, a specific gravity of 2.64 , and an absorption of $1.2 \%$; (3) crushed basalt coarse aggregate with a maximum aggregate size (Dmax) of $13 \mathrm{~mm}$, specific gravity of 2.64 , absorption of $1.0 \%$, and dry-rodded density of $1665 \mathrm{~kg} / \mathrm{m}^{3}$, and (4) ground granulated blast furnace slag with a specific gravity of 2.89 supplied by China Hi-Ment corporation; (5) superplasticizer (SP) conforming to ASTM C494 Type-G with a specific gravity of 1.1 ; and (6) fresh water.

\section{Mixture Proportions}

The mixture proportions used in this investigation were designed to study the effect of abrasion type on concrete using the absolute-volume method. As summarized in Table 1, concrete mixtures were prepared with three different water-tocementitious material ratios $(\mathrm{w} / \mathrm{cm})$ of 0.280 .36 and 0.50 . The cement was partially replaced with $20 \%$ of slag furnace by weight. A superplasticizer was used to produce concrete having roughly the same slump of $22 \pm 2 \mathrm{~cm}$. The compressive strength of concrete was shown in Table 2.

\section{Casting}

For each concrete mixture, the following specimens were cast: (a) Six $\varphi 150 \times 300 \mathrm{~mm}$ cylindrical specimens for compressive strength testing were made and tested in accordance with ASTM C39. (b) Six square slabs, $200 \times 200 \times 50 \mathrm{~mm}$ (thick) for the impact abrasion tests subjected to waterborne sand. The measured average abrasion rate of three plates was designated as the representative data for each concrete mixture for reference use.

Twenty-four hours after casting the samples, they were

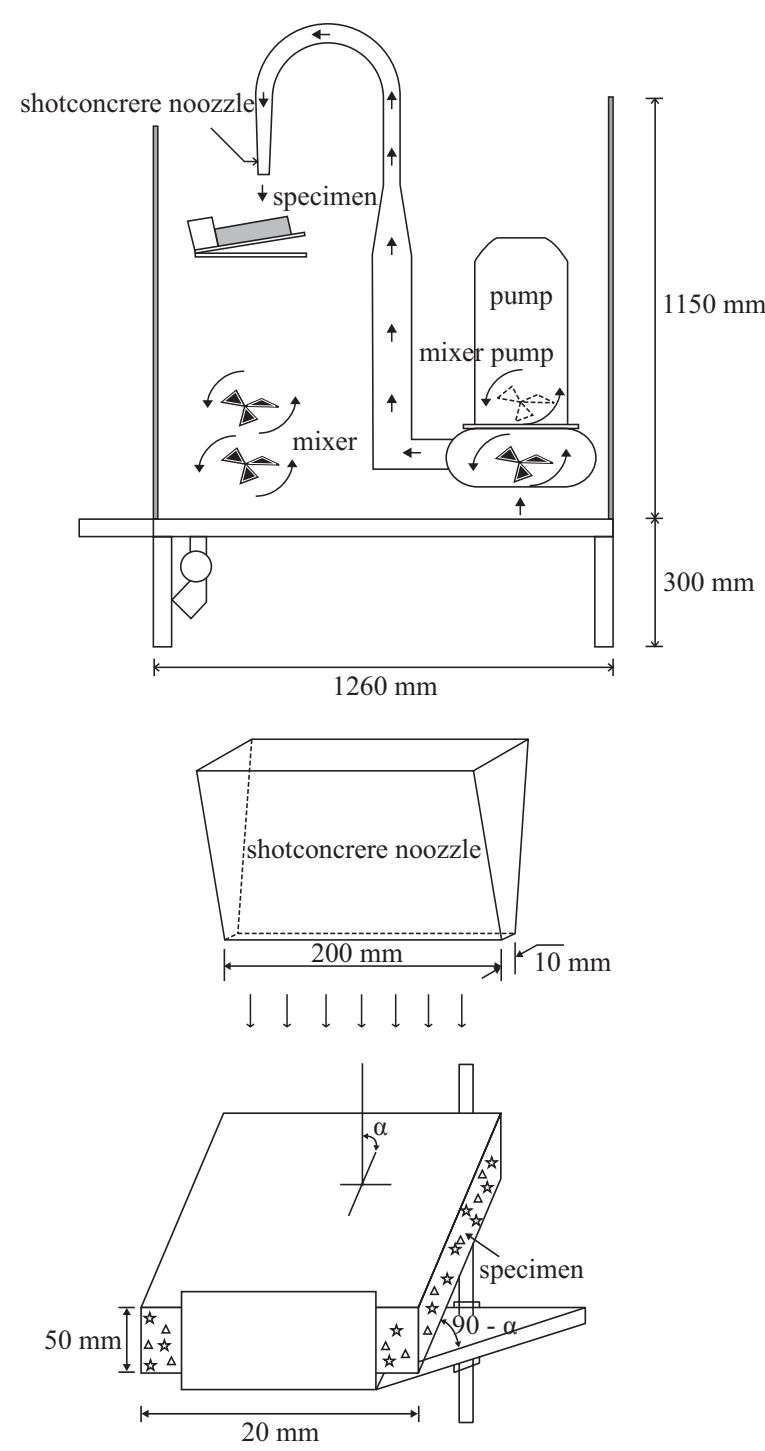

Fig. 1. The waterborne sand flow impact abrasion test apparatus.

stripped and placed under water for curing. Tests were performed after 28 days of water curing.

\section{Experimental Method and Apparatus}

The abrasion tests were carried out in a waterborne sand flow apparatus that is described in Ref. [9]. To understand the interfacial bonding behaviors between coarse aggregate and mortar, a specially designed and fabricated $10 \times 200 \mathrm{~mm}$ rectangular nozzle large enough to cover the maximum aggregate size was used in the waterborne sand tests as shown in Fig. 1. The reason for using a rectangular nozzle is that it produces a water-jet flow of water over a spillway in the field as opposed to a circular flow.

The abrasion tests were carried out in a waterborne sand flow apparatus that is described in Ref. [9]. To understand the interfacial bonding behaviors between coarse aggregate and mortar, a specially designed and fabricated $10 \times 200 \mathrm{~mm}$ rectangular nozzle large enough to cover the maximum aggregate 


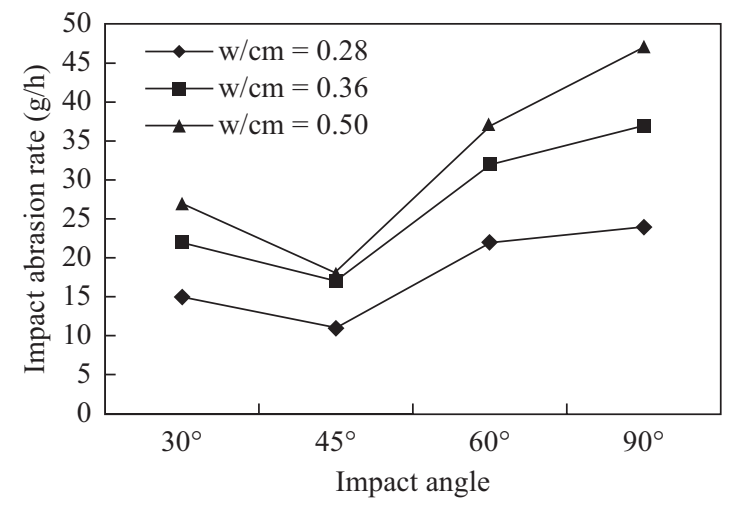

Fig. 2. Abrasion rate versus impact angle for concrete made with $\mathrm{W} / \mathrm{B}=$ 0.5 and 0.36 .

size was used in the waterborne sand tests as shown in Fig. 1. The reason for using a rectangular nozzle is that it produces a water-jet flow of water over a spillway in the field as opposed to a circular flow.

The test water was made by mixing quartz river sand not coarser than $5 \mathrm{~mm}$ to formulate a slurry mixture. During the tests, the nozzle was held at $30^{\circ}, 45^{\circ}$ or $90^{\circ}$ degree angles in relation to the test slab to evaluated the effects of flow angles on the impact abrasion. An abrasion chamber measuring $1260 \times 1150 \times 1170 \mathrm{~mm}$ capable of accommodating four individual pumps that can simultaneously shoot out 4 separate water flows of different sand mixtures at different velocities onto the test slabs that were positioned above water level.

Fresh sand supply was used to make the designed water flows composed of angular quartz tic river sand with Mohshardness (Hp) of 8 and specific gravity of 2.64. In general, sand was gradually poured in and mixed for 5 minutes until the mixture reached a 110,230 or $340 \mathrm{~kg} / \mathrm{m}^{3}$ sand content.

During each water jet test, the cavitations index was first assessed and found to be 0.2 . In accordance with reference [1], a cavitations index of 0.2 is small enough to be ignored. Throughout the $2 \mathrm{hr}$ water jet test, the velocity of water was controlled at $10 \mathrm{~m} / \mathrm{sec}$ that is equivalent to a $0.17 \mathrm{MPa}$ pressure on the test slab and the water temperature was maintained at $30^{\circ} \mathrm{C}$.

Immediately after the test, the loose materials were flushed out and collected to determine their mass with a precision of $\pm 0.05 \mathrm{~g}$. The mass of the slab before $(\mathrm{m} 1)$ and after $(\mathrm{m} 2)$ the test were also measured to determine the impact abrasion loss, and the impact abrasion rate (IAR, in $\mathrm{g} / \mathrm{h}$ ) were determined from the specimen's total mass loss vs. test time. A minimum of three measurements were used to establish the IAR. The range among the test results for the three specimens should be no greater than $45 \%$ of their average.

\section{RESULTS AND DISCUSSION}

\section{Effect of Impact Angle on Aabrasion Rate}

Fig. 2 shows the relationship between $w / \mathrm{cm}$ ratio and impact abrasion loss. The concrete impacted at $45^{\circ}$ and when w/cm ratio increased from 0.28 to 0.36 , then to 0.50 , the average impact abrasion rate increased by approximately $54 \%$ and $64 \%$, respectively. As for the same mixture proportions, but impacted at $90^{\circ}$, the gains in wear resistance were nearly $54 \%$ and $96 \%$, respectively. The results reveal that concrete of low strength can be worn out easily by water jet and can subsequently develop additional porosity, constituting an undesirable cycling effect. In contrast, a low w/cm concrete that is usually made by adding silica fume as micro-filler and Pozzolanic material can substantially reduce the overall porosity and pore sizes, and can strengthen the bond between particles of the hydrated matrix [13]. A low w/cm concrete perform better in resisting impact abrasions. In addition, the impact abrasion loss was also influenced by the impact angle. At the end of $2 \mathrm{hr}$ of testing and with $\mathrm{w} / \mathrm{cm}$ ratio $0.28,0.36$ and 0.50 , the impact abrasion rate of concrete impacted at $90^{\circ}$ was nearly $38 \%, 41 \%$, and $43 \%, 54 \%, 54 \%$, and $62 \%$, and $8 \%$, $14 \%$, and $21 \%$, higher than that of $30^{\circ}, 45^{\circ}$ and $60^{\circ}$, respectively. This may explain why the hydraulic pressure and its associated particle prising action on concrete impacted at $90^{\circ}$ are higher than of that of other angle, thus increasing the impact abrasion loss.

Observations on the specimen after being subjected to a waterborne sand jet test reveal that transient hydraulic rim pulls impinged on the specimen and caused local tensile stresses in the top layer of the exposed concrete. Based on the energy conservation theory, the intensity of the tensile stresses varied in respect to the impact momentum of the hydraulic jet forces. These tensile stresses are the prime culprits for causing cracks in the hardened mortar and fractures around aggregate particles which eventually lead to impact abrasion.

Fig. 3 shows photos from various impact abrasions of the concrete after testing. The matrix exhibits significant indenting by the exposed erodent, the aggregate grain appears to peel away and the mortar on which interfacial cracks become visible on the concrete prepared with high $\mathrm{w} / \mathrm{cm}$ and impacted at $90^{\circ}$ (Fig. 3a), whereas it appears to be rather smooth in low w/cm concrete and impacted at $45^{\circ}$ (Fig. $3 \mathrm{~b}$ ). The SEM revealed the cracks formed in the cement matrix and the interface between aggregate grain and cement matrix shown in Fig. 4a for concrete impacted at $90^{\circ}$. The mortar was be abraded easily, with concomitant smearing of the surface, and formation of many small cracks rather than a few large ones. In addition, the concrete impacted at $90^{\circ}$ displayed a rougher and more rugged surface than concrete impacted at $45^{\circ}$ and $30^{\circ}$ (Figs. $4 \mathrm{~b}$ and $4 \mathrm{c}$ ).

A fundamental approach was to obtain the brittle abrasion deals with material removal due to crack formation, while ductile abrasion deals with material removal due to cutting and plowing [14]. For concrete, it is generally considered that abrasion damage is the gradual removal of material caused by repeated deformation and cutting action. The theoretical analysis for cutting $[10,12]$ shows that progressive cutting occurs at a given low impact angle, under which a particle may slip on a surface or it may retain some of its own impact 


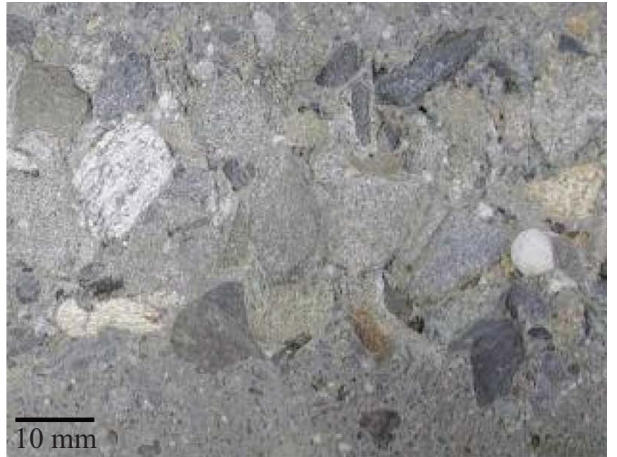

(a) $\mathrm{w} / \mathrm{cm}=0.50$, impacted at $90^{\circ}$

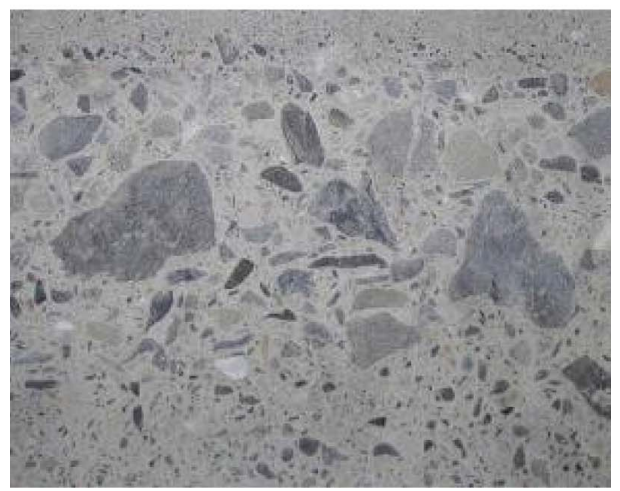

(b) $\mathrm{w} / \mathrm{cm}=0.28$, impacted at $45^{\circ}$

Fig. 3. Images of worn concrete surfaces under various conditions.

energy after the impact, resulting in a decreased in material removal. Moreover, the abrasion rate is associated with the relation between the shear force to cut a mass of material and the material resistance indicated by the compressive strength or hardness. For the concrete impacted by waterborne sand flow the abrasion action mainly include pre-abrasion peeling by water molecules and its associated hydraulic pressure, solid particle impact, edge effect and prising. For the concrete specimen impacted at $90^{\circ}$ the crack.

Formation due to normal component of impact velocity dominated material removal, while impacted at $30^{\circ}$ the cutting dominated material removal. For waterborne sand flow test, it can be found that the abrasive force due to normal component of impact velocity is higher than the cutting. With impact at $45^{\circ}$, SEM revealed that the indentation of the surface was insignificant compared with impact at $30^{\circ}, 60^{\circ}$ and $90^{\circ}$, reducing less material loss.

\section{Effect of Erodent Size on Abrasion Rate}

The erodent size is significant influence of abrasion damage of concrete surfaces, as shown in Fig. 5. From Fig. 5, we can see clearly that there was abrasion slight on concrete surfaces as erodent size of $0.6 \mathrm{~mm}$, but the abrasion damage was serious as erodent size of $5 \mathrm{~mm}$. When the erodent size increased from $0.6 \mathrm{~mm}$ to $1.2 \mathrm{~mm}, 2.5 \mathrm{~mm}$, then to $5 \mathrm{~mm}$, the abrasion rate of concrete made with $\mathrm{w} / \mathrm{cm} 0.36$ and impacted at $45^{\circ}$, increased from $100 \%$ to $217 \%$ and $367 \%$, respectively. When
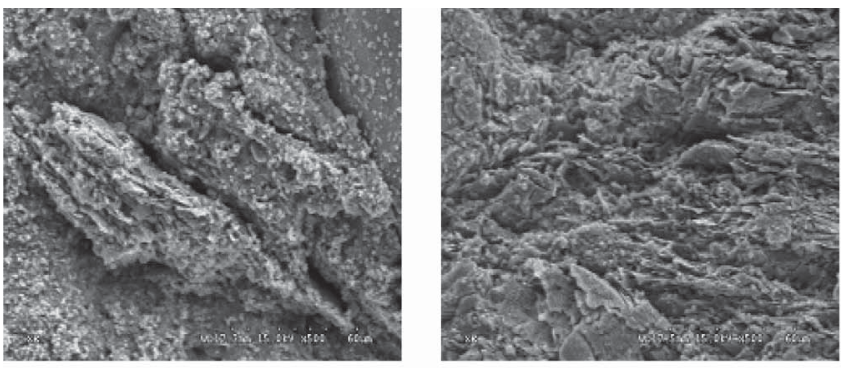

(a) $90^{\circ}$
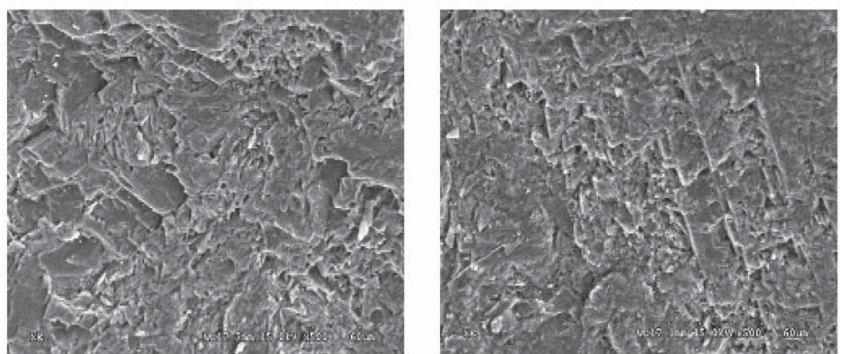

(b) $45^{\circ}$

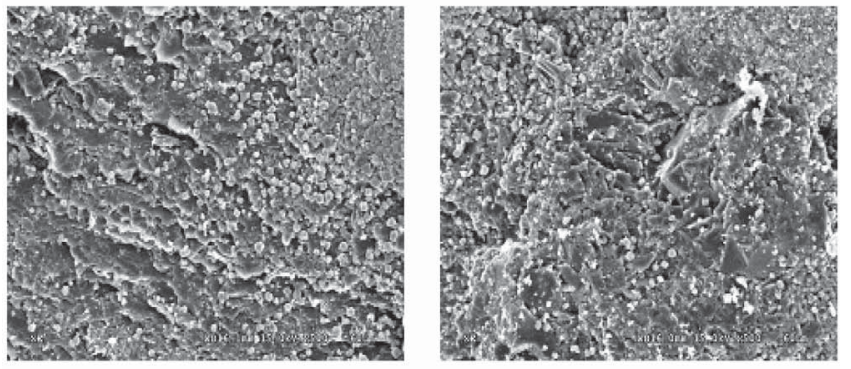

(c) $60^{\circ}$
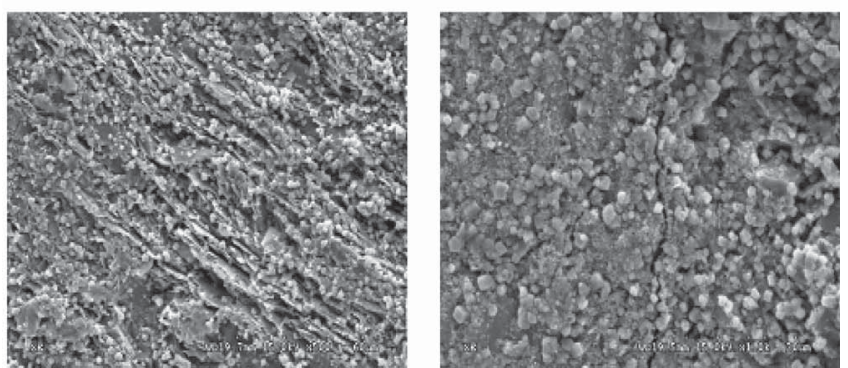

(d) $30^{\circ}$

Fig. 4. SEM-images of worn concrete surface $(\mathrm{w} / \mathrm{cm}=0.36)$, scale: $60 \mu \mathrm{m}$. Impacted at (a) $90^{\circ}$, (b) $45^{\circ}$, (c) $60^{\circ}$ and (d) $30^{\circ}$.

abrade size is decrease, eventually the abrade particles are not able to initiate cracking and will only plastically deform the target. Theories of abrasion of brittle materials, which are based on elastic-plastic interactions [5], predict impact abrasion rate $\alpha$ abrade size. The experimental data for concrete specimens show a distinct relationship between the abrasion rate and the abrade size. It can be approximated by a linear regression of impact abrasion rate $\alpha$ abrade size with a regression coefficient of $\mathrm{R}^{2}=0.9627$, as shown in Fig. 6 . The deviations from the ideal are common and are usually related to interfacial, microstructural and flaw effects. Moreover, the 


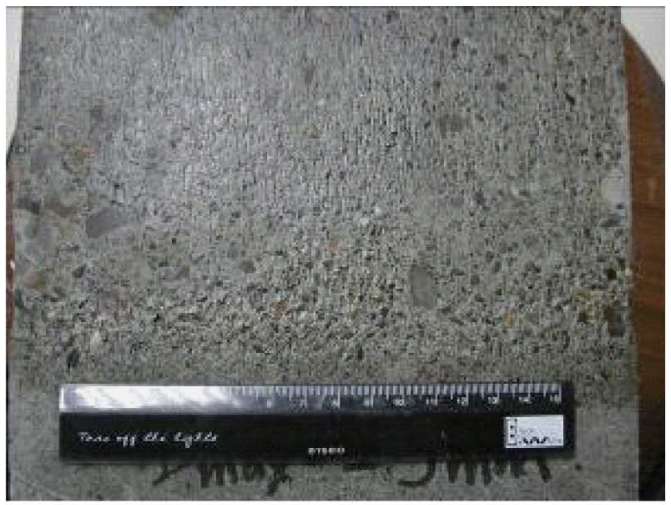

$0.6 \mathrm{~mm}$

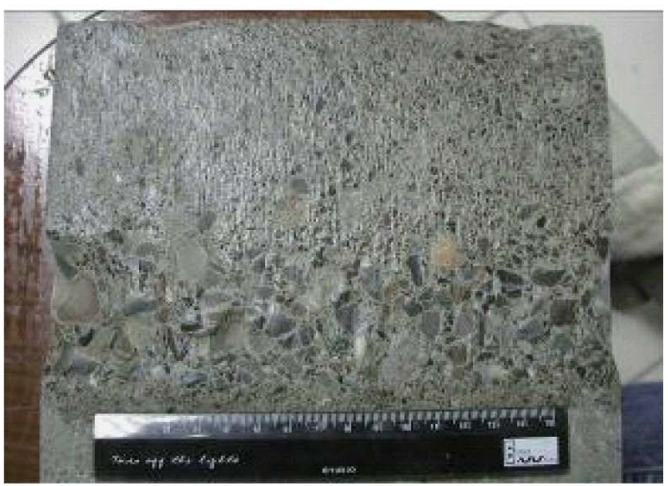

$1.2 \mathrm{~mm}$

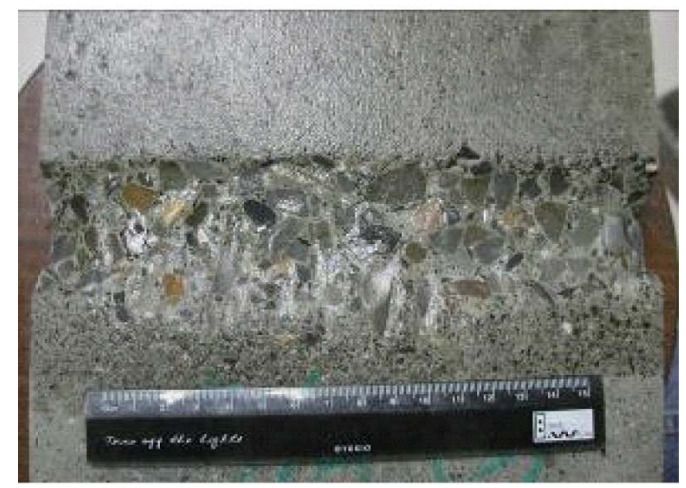

$2.5 \mathrm{~mm}$

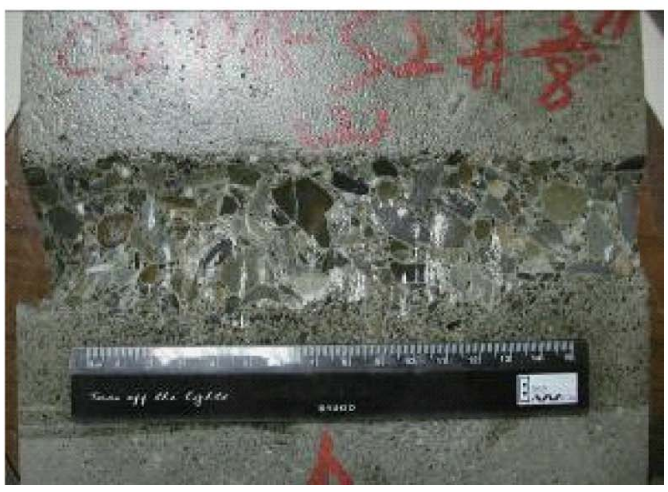

$5.0 \mathrm{~mm}$

Fig. 5. Images of worn concrete surfaces under various erodent size $\left(\mathrm{w} / \mathrm{cm}=0.36\right.$, impacted at $\left.45^{\circ}\right)$.

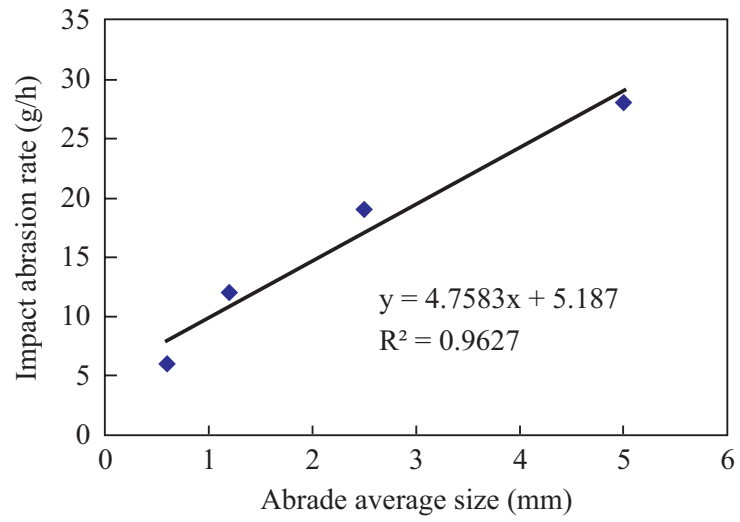

Fig. 6. Abrasion rate versus abrade average size for concrete made with w/cm $=0.36$, impacted at $45^{\circ}$.

water flow due to establishment of a stagnation pressure enters pre-existing flaws in the material, especially micro-cracks in the interfacial zones between paste and aggregate.

\section{Effect of Sand Content on Abrasion Rate}

Whether the water flow contains sand or not make difference significantly to concrete abrasion. We can see clearly from Fig. 5 that there was not nearly abrasion damage on concrete surface as the water contents none sand. However, the sand content of water flow increased the abrasion loss of concrete increased. Due to the density of sand particle are larger than water the impact engine raise on concrete surface, and result in abrasion loss of concrete increase. As the sand content of water flow is 110,230 and $340 \mathrm{~kg} / \mathrm{m}^{3}$, concrete impacted at $45^{\circ}$ and $90^{\circ}$, the abrasion rate is 10,17 and 23 times, and 23, 37 and 57 times of none sand water, respectively, as show in Fig. 8. On the other hand, as concrete impacted at $90^{\circ}$, the sand content of water flow increased, the increase of abrasion rate is larger than concrete impacted at $45^{\circ}$.

\section{CONCLUSION}

Solid-particle abrasion rate of concrete depended strongly on abrade size, impact angle and sand content of water. The abrasion rate was highest at $90^{\circ}$ impact, secondly at $60^{\circ}$ and $30^{\circ}$ impact, and lowest at $45^{\circ}$ impact. As the erodent size increased from $0.6 \mathrm{~mm}$ to $1.2 \mathrm{~mm}, 2.5 \mathrm{~mm}$, then to $5 \mathrm{~mm}$, the abrasion rate of concrete increased from $100 \%$ to $217 \%$ and $367 \%$. It can be approximated by a linear regression of impact abrasion rate $\alpha$ abrade size with a regression coefficient of $\mathrm{R}^{2}=0.9627$. Moreover, the abrasion rate increase significantly as water flow contain sand compare with none sand water flow and the sand content of water flow increased the abrasion loss of concrete increased. For the concrete impacted by waterborne sand flow the abrasion action mainly includes pre-abrasion peeling by water molecules and its associated hydraulic pressure, solid particle impact, edge prising material loss in concrete appears to have been caused by a complex combination of fracture mechanisms. 


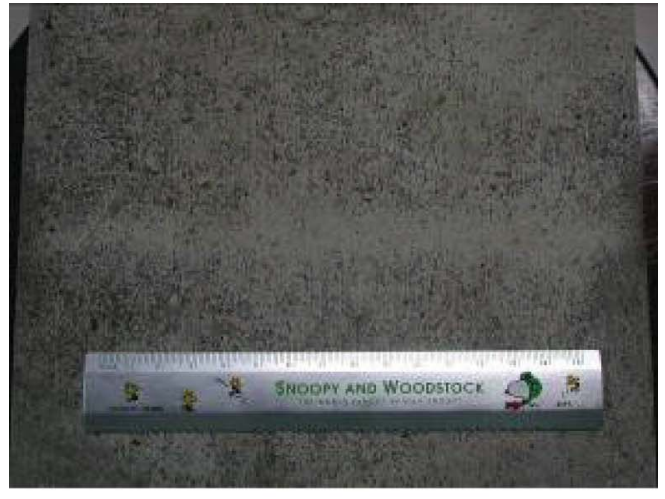

$0 \mathrm{~kg} / \mathrm{m}^{3}$

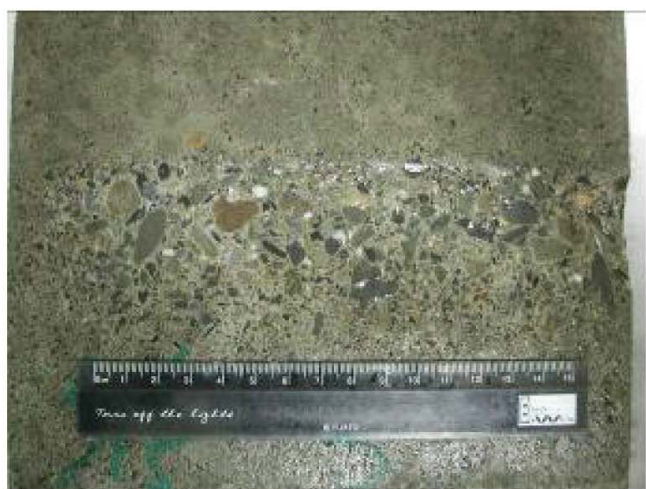

$110 \mathrm{~kg} / \mathrm{m}^{3}$

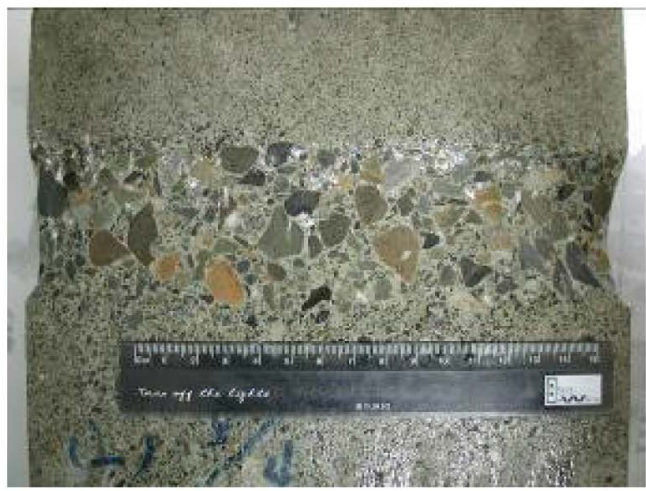

$230 \mathrm{~kg} / \mathrm{m}^{3}$

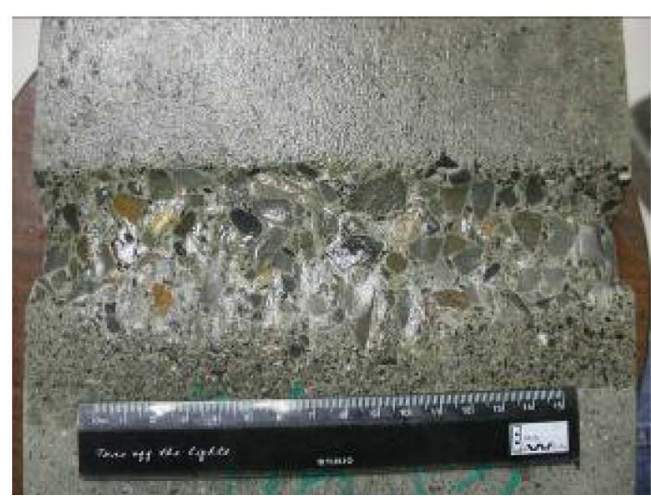

$340 \mathrm{~kg} / \mathrm{m}^{3}$

Fig. 7. Images of worn concrete surfaces under various sand content $\left(w / c m=0.36\right.$, impacted at $\left.45^{\circ}\right)$.

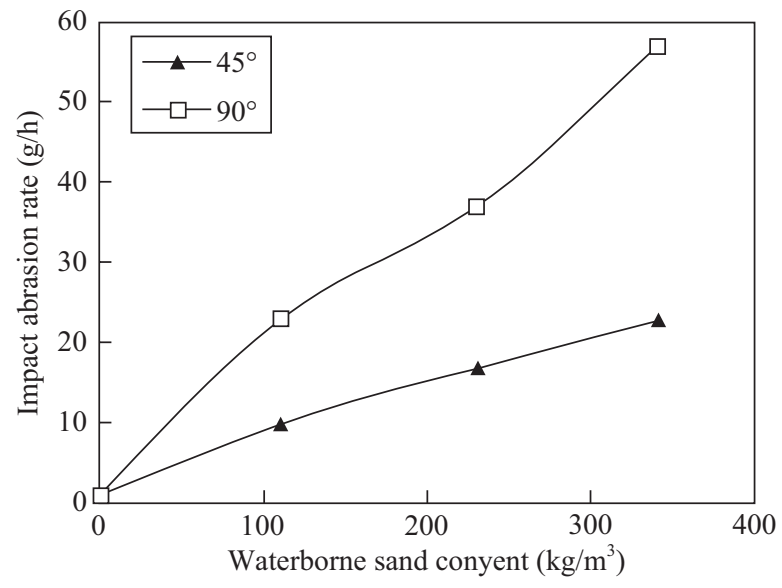

Fig. 8. Abrasion rate versus sand content for concrete made with $\mathrm{w} / \mathrm{cm}=$ 0.36, impacted at $45^{\circ}$.

\section{ACKNOWLEDGMENTS}

This paper was supported by the Taiwan National Science Council under NSC 94-2211-E-415-003.

\section{REFERENCES}

1. ACI Committee 210, Erosion of Concrete in Hydraulic Structure (ACI 210R-93), ACI Manual Concrete Practice, Part 1, American Concrete Institute, Farmington Hills, MI (1993).

2. ASTM Designation C1138, "Standard test method for abrasion resistance of concrete (underwater method)," American Society for Testing and Materials, Philadelphia (1998).

3. Blau, P. J. and Budinski, K. G., "Development and use of ASTM standards for wear testing," Wear, Vols. 225-229, pp. 1159-1170 (1999).

4. Council of Agriculture, "Taiwan soil and water preservation code," http://river.nchu.edu.tw (2004).

5. Evans A. G., Gulden, M. E., and Rosenblatt, M., "Impact damage in brittle materials in the elastic-plastic response regime," Proceedings of the Royal Society, Vol. 361, pp. 343-365 (1987).

6. Goretta, K. C., "Solid-particle erosion of Portland cement and concrete," Wear, Vol. 244, No. 1, pp. 106-112 (1999).

7. Henk, W. and Miko, C. E., "A closer look at the ductile-brittle transition in solid particle erosion,” Wear, Vol. 253, No. 9, pp. 1035-1043 (2002).

8. Hocheng, H. and Weng, C. H., "Hydraulic erosion of concrete by a submerged jet," Journal of Materials Engineering and Performance, Vol. 11, No. 3, pp. 256-261 (2002).

9. Liu, Y. W., Yen, T., and Hsu, T. H., "Abrasion erosion of concrete by waterborne sand," Cement and Concrete Research, Vol. 36, pp. 1814 1820 (2006).

10. Momber, A. W., Water Jet Applications in Construction Engineering, A.A. Balkema, Rotterdam, Netherlands (1998).

11. Munoz, A. A. and Sheng, P., "An analytical approach for determining the environmental impact of machining processes," Journal of Materials Processing Technology, Vol. 55, Nos. 3-4, pp. $736-758$ (1995).

12. Oka, Y. I., Ohnogi, H., Hosokawa, T., and Matsumura, M., "The impact angle dependence of erosion damage caused by solid particle impact," Wear, Vols. 203-204, pp. 573-579 (1997).

13. Plum, D. and Fang, X., "A rock and a hard place," International Water Power \& Dam Construction, Vol. 48, pp. 30-33 (1996).

14. Sheldon, G. L. and Finnie, I., "On the ductile behavior of nominally brittle materials during erosion cutting," Journal of Engineering for Industry, Vol. 88, pp. 387-392 (1966). 